\title{
Foucault, a genealogia, a história da educação
}

Foucault, the genealogy, the history of education

Foucault, la genealogía, la historia de la educación

\author{
Organização \\ Haroldo de Resende \\ Universidade Federal de Uberlândia (Brasil) \\ https://orcid.org/0000-0001-9379-111X \\ http://lattes.cnpq.br/5363115483274501 \\ haroldoderesende@ufu.br \\ Julio Groppa Aquino \\ Universidade de São Paulo (Brasil) \\ https://orcid.org/0000-0002-7912-9303 \\ http://lattes.cnpq.br/1124623998211027 \\ groppaq@usp.br
}

\section{Apresentação}

Nietzsche, a genealogia, a história é um dos textos mais célebres de Michel Foucault. Por meio de uma espécie de homenagem e, ao mesmo tempo, uma apropriação teórico-prática, o pensador francês tributa a Nietzsche seu empreendimento de uma história genealógica, no qual passam a ocupar lugar - a par do que nomeia sentido histórico ou história efetiva - a inconstância e a provisoriedade dos acontecimentos, em oposição tanto à restituição essencial das coisas, quanto ao reencontro de uma identidade perpétua ou, ainda, ao reconhecimento da unidade universal do sujeito antropológico.

A proposição deste dossiê Foucault, a genealogia, a história da educação busca, em alusão direta ao texto de Foucault, congregar abordagens e reflexões em íntima articulação à análise histórico-genealógica proposta por Foucault, de maneira a focalizar criticamente os jogos veridictivos envolvidos na investigação educacional contemporânea.

Margareth Rago - uma das pesquisadoras brasileiras pioneiras no que se refere não apenas à utilização do referencial teórico-prático da genealogia de Foucault, mas também ao enfrentamento do debate historiográfico, deslocando a análise dos fatos e dos acontecimentos para os fundamentos epistemológicos do discurso com vistas à compreensão dos campos de relações de força em que os jogos de poder se constituem - é a responsável pelo texto que abre o dossiê, o qual revisita, 25 anos depois, o texto As Marcas da Pantera: Michel Foucault na Historiografia Brasileira $^{1}$, também de sua autoria. Por se tratar de uma das primeiras iniciativas desse tipo de

\footnotetext{
${ }^{1}$ Disponível em: https://periodicos.sbu.unicamp.br/ojs/index.php/resgate/article/view/8647987. Acesso em 06 abr. 2020.
} 
discussão no Brasil, o referido texto tornou-se uma leitura obrigatória para estudiosos e pesquisadores que buscam fazer apropriações das formulações genealógicas nas diversas ramificações de campos da História e em outros campos afins.

Desse modo, desdobrando as discussões e ampliando as reflexões a partir de escritos e ditos de Foucault que foram publicados nos últimos anos, Rago atualiza, de maneira bastante abrangente, a análise acerca do conceito de poder nos deslocamentos operados por Foucault: da disciplina, do biopoder e da biopolítica para o governo de si e dos outros na condução das condutas, a partir do que aponta para os modos de subjetivação e para as contracondutas, permitindo a percepção de outros modos pelos quais as práticas da liberdade são experimentadas em face da governamentalidade cristã ou neoliberal. Por isso, As marcas da pantera, 25 anos depois..., ao abrir o dossiê, funciona como uma espécie de patamar a partir do qual são lançadas as reflexões dos outros artigos que o compõem, buscando cumprir com seu propósito de reunir um conjunto de discussões capazes de contribuir para o debate sobre a genealogia de Foucault na História da Educação.

$\mathrm{O}$ texto seguinte, A genealogia de Michel Foucault e a história como diagnóstico do presente: elementos para a História da Educação, tomando como base o próprio texto de Foucault que inspira este dossiê, busca desenvolver questões relativas ao projeto de uma história genealógica. A partir disso, traça uma discussão sobre a articulação de marcos teóricos da genealogia foucaultiana com a efetivação da História da Educação, desenvolvendo um argumento que aponta para a pertinência do uso do referencial genealógico no campo da história e da historiografia da educação. Considera, por fim, que a incorporação de noções genealógicas na pesquisa e na produção do conhecimento em História da Educação pode trazer ampliações teórico-metodológicas que, certamente, representam uma contribuição para o delineamento de outros contornos no que diz respeito à compreensão das formas de organização e funcionamento da educação em nossa sociedade, assim como ao entendimento da genealogia como ferramenta histórico-crítica da atualidade, naquilo que Foucault propõe como ontologia do presente, como interrogação da verdade sobre seus efeitos de poder e do poder sobre os discursos de verdade, especialmente no campo educacional.

Inés Dussel com o objetivo realizar uma análise tanto das perspectivas historiográficas como de contribuições para uma compreensão mais abrangente da emergência e dos efeitos da instituição escolar, associando Foucault com o autor pós-foucaultiano Ian Hunter, propõe em seu artigo uma releitura das posições de Foucault sobre a história da escola e uma abordagem do livro Repensando a escola. Subjetividade, Burocracia, Crítica, de Ian Hunter. Assim, a autora opera uma breve reconstituição da história da escolarização na abordagem foucaultiana, assim como apresenta a sua leitura do texto de Ian Hunter, o qual hipotetiza sobre o surgimento da instituição escolar. Em seguida, são apresentados alguns debates suscitados por essa obra entre historiadores e filósofos educacionais. Por fim, a autora propõe perspectivas de linhas de trabalho para a contunuidade do aprofundamento do diálogo com o empreendimento genealógico de Foucault a partir da história da escolarização.

Sob o argumento de que "Uma história da educação em chave genealógica é uma genealogia das práticas pedagógicas", assim como o de que "uma genealogia das práticas pedagógicas modernas é, finalmente, uma história da modernidade em chave genealógica", Carlos Ernesto Noguera-Ramírez e Dora Lilia Marín-Díaz apresentam sua contribuição para o dossiê com o propósito de discutir o conceito de "educacionalização do mundo" estabelecido por Tröhler, segundo o qual a modernidade corresponderia à educacionalização do mundo. Reconhecem, assim, a importância e o potência do conceito de educacionalização tanto para a História da Educação quanto para a Pedagogia como um todo. O texto dos dois pesquisadores objetiva realizar a descrição da origem e da emergência de matrizes normativas da modernidade que sustentam o que Tröhler denomina "virada educacional"; esta relida à luz de ferramentas arqueológicas estabelecidas por Foucault. Como principal resultado da investida, os autores 
afirmam, dierentemente de Tröhler, que o surgimento da educação do mundo não não se deu entre os séculos XVIII e XIX, mas entre os séculos XVI e XVII, no marco daquilo que Foucault cunhou como "era da governamentalidade". Desse modo, Noguera-Ramírez e Marín-Díaz realizam um exercício histórico-filosófico por meio do qual evidenciam uma perspectiva valiosa para a reflexão sobre a educação e a pedagogia, bem como para a análise das práticas pedagógicas, segundo a problemática posta pela governamentalidade e pelo ascetismo.

Por sua vez, José G. Gondra realiza uma crítica genealógica ao pôr em questão as relações de poder que atravessam as narrativas discursivas. Dessa forma, ele explora alguns princípios narrativos que constituem o manual Noções de História da Educação, de autoria do polígrafo, Afrânio Peixoto, reeditado sucessivamente nos anos de 1933, 1936 e 1942, o qual se apresenta como resultado dos três anos (1932-1934) que o autor se dedicou ao ensino de História da Educação no Instituto de Educação do Rio de Janeiro. Na narrativa construída no manual, Peixoto lega para as futuras professoras o que chama de "história da civilização", uma espécie de capital cultural que ele considerava fundamental para a compreensão do passado mais remoto e outros presentes, definindo assim uma condição para a obtenção de uma maior profissionalização da docência. Gondra investe no trabalho do registro de algo como uma origem da escola, uma fundação original que operaria com marcos fundamentais, cujo propósito seria a comprovação da substância e das funções desse acontecimento primordial. Assim, o exercício realizado busca desfazer a imobilidade de uma identidade e funcionamento da escola, perpetuando uma essência e suspendendo o tempo. Busca, pois, pensar as opções e operações historiográficas, assim como o movimento pedagógico ao qual o manual de Peixoto se conecta e que, por sua vez, também ajuda a legitimar e reproduzir. Gondra conclui que as tantas (des)continuidades que atravessam e regulam o nosso tempo presente e de modos bastante diversos são possíveis de serem observadas tanto na sociedade assim como nas escolas e, especificamente, na formação de professores, o que pode indicar que aquilo que o passado ensina, por intermédio de noções de história da educação, é o traçado de itinerários nada previsíveis e fora de qualquer teleologia predestinada.

$\mathrm{O}$ último artigo do dossiê, intitulado Foucault e a História da Educação brasileira: dos usos possíveis do procedimento genealógico, tendo como horizonte o procedimento investigativo foucaultiano delineado no texto Nietzsche, a genealogia, a história, propõe-se a pôr em perspectiva as repercussões do legado de Michel Foucault, no que diz respeito à utilização de ferramentas genealógicas na produção bibliográfica em História da Educação no período de 1997 a 2017, nos três periódicos brasileiros voltados especificamente ao campo histórico-educacional. A análise recaiu sobre 42 artigos selecionados, de maneira a dar a ver movimentos simultâneos, numa análise de conjunto. Na dissecação do corpus analítico escolhido, não se pretendeu realizar nenhuma comparação entre o que Foucault realizou e os traçados investigativos dos historiadores da educação brasileiros, de sorte que foi realçada a potência da circulação de novas narrativas históricas, por meio da qual desponta a reinvenção de ferramentas já tantas vezes utilizadas e reutilizadas. Desse modo, as conclusões voltam-se para as condições de tempo, lugar e modos que cercam os exercícios de investigação histórica que buscam inspiração teórico-prática em Michel Foucault.

Por fim, é preciso sublinhar que o presente dossiê reúne um conjunto de textos que apresentem repercussões possíveis da questão genealógica no campo da história da educação: as contingências das formas educacionais; os deslocamentos da organização e do funcionamento do aparelho escolar; as estratégias de governamento dos sistemas de ensino, assim como as concepções de conhecimento que sustentam os fazeres pedagógicos e, em última instância, aquelas próprias da História da Educação. Articulando a análise genealógica ao campo específico da história da educação, a intenção é, de algum modo, dispor chaves outras de compreensão do presente educacional e suas interpelações tantas. 